\title{
Mudança tecnológica e definição da agenda de políticas públicas: regulação para universalização da banda larga no Brasil
}

Technological Change and Public Policy Agenda Setting: The Broadband Regulation for Universalization in Brazil

\section{Resumo}

A proposta deste trabalho é analisar a influência da mudança tecnológica na formação de agendas de políticas públicas, em especial de agendas regulatórias. Para tanto, analisa como os avanços tecnológicos no setor de telecomunicações foram alterando as formas de comunicação da sociedade e impondo a necessidade de constantes mudanças no escopo da agenda da regulação para universalização da telefonia fixa para banda larga. Esta análise se baseia em revisão bibliográfica sobre o tema, apoiada em artigos, livros e relatórios, bem como na legislação brasileira do setor de telecomunicações. Observa-se que, em setores tecnologicamente dinâmicos, como o setor de telecom, as agendas regulatórias para universalização sempre estarão em descompasso com os avanços tecnológicos. Com isso, ressalta-se a importância de que essas agendas sejam constantemente revistas, de modo que o regulador possa sempre garantir a massificação do acesso a serviços de telecomunicação que estejam em linha com os avanços tecnológicos do setor.

\section{Abstract}

This paper analyzes the influence of technological change on the public policy agenda setting, especially on the regulatory agenda. In doing so, it analyzes how technological changes that took place in the telecommunication sector have altered the forms of communication in society and how they have imposed changes on the scope of regulatory agenda for universalization (from fixed telephony to broadband services). This analysis is based on a bibliographical and legal framework review. One can observe that, considering technologically dynamic sectors, as telecom, the regulatory agenda for universalization is at odds with technical changes. Thus the constant revision of these agendas is of major importance, so the regulatory entity

*Doutoranda em Teoria Econômica pela Unicamp. Mestre em Política Científica e Tecnológica pelo Departamento de Política Científica e Tecnológica da Unicamp. Pesquisadora do Núcleo de Economia Industrial e da Tecnologia (NEIT-IEUnicamp). 
can guarantee that the universalization of telecom services will constantly be in line with its technological advances.

Palavras-chave: mudança tecnológica, agenda política, universalização, banda larga. Keywords: technological change; public agenda; universalization; broadband.

\section{Introdução}

As políticas públicas são comumente compreendidas como instrumentos de mediação de conflitos sociais, que podem tomar a forma de um programa de ação governamental, sendo designado a determinado setor específico da sociedade e objetivando o bem-estar da população (Romano, 2009, Muller, 2009 e Pereira, 2008).

A formação da agenda política é uma etapa importante do processo de implementação de políticas públicas, porque norteia e define os problemas a serem levados a cabo por programas de ação governamental. No entanto, os processos pré-decisórios da definição da agenda permanecem como uma questão ainda pouco explorada na análise de políticas públicas (Kingdon, 2006).

Este trabalho busca identificar quais são os fatores desencadeadores de agendas de políticas públicas, ou como e que tipos de problemas são percebidos pelos agentes envolvidos no processo de construção social e político de agendas como relevantes para obterem o status de agenda formal de políticas públicas em detrimento de outros.

Neste trabalho, é explorada a ideia de que a mudança tecnológica origina novos problemas que as agendas de políticas são obrigadas a encarar, abrindo, portanto, janelas para a definição de novas políticas públicas ou alteração de antigas. Toma-se como base o processo recente de inovação tecnológica no setor de telecomunicações, representado pela digitalização das antigas redes analógicas de comunicação, que, ao vincularem a transmissão de voz, dados e mídia em plataformas únicas de transmissão, aumentaram a percepção da importância do acesso à plataforma Internet Protocol (IP) em banda larga, levando à inclusão desse item na agenda de universalização da banda larga no país em detrimento das anteriores metas de universalização dos serviços de voz. 
Para tanto, a primeira seção deste trabalho apresenta, brevemente, o papel das políticas públicas - sua raison d'être e seu modus operandi enfatizando-se, de forma mais específica, sua conceituação, formulação e etapas de implementação. Na segunda seção, é destacada a etapa de formação da agenda de políticas públicas, identificando-se de que forma essa agenda se estabelece, quais são seus condicionantes e tipos de influências. Na terceira e última seção, analisa-se a influência da mudança tecnológica na formação ou alteração de agendas de políticas públicas, tomando-se como exemplo as transformações que a digitalização das redes de telecomunicações e a crescente importância e essencialidade da banda larga impuseram nas agendas de políticas públicas voltadas à universalização desse serviço no Brasil.

\section{Conceituação, formulação e implementação das políticas públicas}

De acordo com Romano (2009), as políticas públicas poderiam ser entendidas como ações ou propostas de regulação dos problemas e das contradições que afrontam as sociedades contemporâneas. Assim, toda política pública se expressa na forma de um processo conflituoso de alocação pública de recursos e oportunidades entre os diferentes grupos sociais com interesses em disputa.

As políticas públicas são mecanismos de gerenciamento dos antagonismos setoriais resultantes da divisão do trabalho. Esses antagonismos surgem, de acordo com Muller (2009), porque cada setor, ao desenvolver sua própria lógica de reprodução, estabelece seus objetivos setoriais como finalidades últimas. Essa sociedade setorial, em desequilíbrio perpétuo, gera, permanentemente, problemas, conflitos, disfunções ou efeitos perversos que devem ser objeto de políticas públicas. $\mathrm{O}$ gerenciamento desses antagonismos se dá sob a forma do estabelecimento de um programa de ação governamental em um setor da sociedade ou em um espaço geográfico.

Mény e Thoenig (1989) apontam cinco elementos que fundamentam a existência de uma política pública: (i) é constituída de um conjunto de medidas concretas, que formam sua substância; (ii) compreende as decisões de natureza mais ou menos autoritária, que podem ter dimensão explícita (jurídica, política) ou latente, pela definição de critérios de acesso ou 
direitos; (iii) se inscreve dentro de uma moldura geral de ação, que permite distingui-la de simples medidas isoladas; (iv) é direcionada a um público, seja ele indivíduos, grupos ou organizações que serão por ela afetados; (v) define obrigatoriamente as metas ou objetivos a serem alcançados. Além disso, uma política pública pode ter igualmente a forma de uma não-decisão.

De acordo com Pereira (2008), políticas públicas também podem ser definidas como processos normativos que objetivam o bem-estar da população, quer sejam políticas de cunho mais genérico, como políticas de Estado Nacional ou de comércio exterior, ou políticas mais específicas, como medidas de seguridade social ou prestação de serviços públicos universais - também considerados como políticas sociais -, cujos exemplos clássicos se encontram nas áreas da saúde, do saneamento básico, dos transportes ou das telecomunicações.

A discussão, formulação e implementação de políticas públicas compreende, conforme afirma Ramos (2010), uma complexa dinâmica entre estrutura e conjuntura, ou seja, entre invariâncias e variâncias de ordem institucional, sócio-cultural e político-econômica, que são fatores imprescindíveis tanto para a compreensão quanto para o êxito das políticas públicas.

Em geral, o desenvolvimento das políticas públicas ou de programas de ação pública segue um padrão sequencial identificado por cinco etapas segundo Jones (1970):

1. Identificação do problema: percepção do problema, definição, agregação de diferentes eventos ou problemas, organização das estruturas governamentais, da representação de interesses e de definição da agenda.

2. Desenvolvimento do programa: associação dos processos de formulação (dos métodos e das soluções para resolver o problema) e de legitimação (aquisição de um consentimento político).

3. Implementação do programa: compreende a organização dos métodos de trabalho, a interpretação das diretivas governamentais e a sua aplicação propriamente dita.

4. Avaliação do programa: especificação dos critérios de julgamento, mensuração e análise dos dados, formulação de recomendações.

5. Término do programa: supõe a resolução do problema e o encerramento das ações. 
A abordagem sequencial de Jones tem algumas limitações, sendo criticada por Muller (2009) como uma análise excessivamente simplista das políticas públicas. Em determinados programas, a ordem das etapas de ação pode ser invertida, ou mesmo suprimida, além disso, certas etapas são, algumas vezes, muito difíceis de serem identificadas.

Frey (2000) propõe uma subdivisão um pouco mais sofisticada das fases do ciclo político [policy cycle], composta de: a) percepção e definição de problemas; b) montagem da agenda; c) elaboração de programas e decisão; d) implementação de políticas; e) avaliação de políticas; e f) eventual correção da ação.

A primeira fase é aquela em que o problema político é percebido pela primeira vez. Isso pode ocorrer por parte de grupos isolados, grupos políticos, pela própria administração pública, ou ainda pela mídia ou por outras formas de comunicação que terminam por dar relevância a um problema em particular. No entanto, de acordo com Windhoff-Héritier (1987:68 apud Frey, 2000), "somente a convicção de que um problema social precisa ser dominado política e administrativamente o transforma em um problema de policy".

$\mathrm{Na}$ segunda fase do ciclo político é que isso se define. De acordo com Frey (2000), nessa fase, é decidido se determinado tema deve ser incluído na pauta política atual ou se deve ser adiado para uma data posterior. Para se tomar essa decisão, geralmente são estabelecidas avaliações preliminares sobre custos e benefícios das várias opções disponíveis de ação, assim como uma avaliação das chances do tema ou projeto se impor na arena política.

$\mathrm{Na}$ terceira fase, em que são elaborados os programas, é preciso escolher a mais apropriada dentre as alternativas de ação. Isso ocorre a partir do estabelecimento de processos de conflito e acordos envolvendo, ao menos, os atores mais influentes na política e na administração.

$\mathrm{Na}$ quarta fase, de implementação de políticas, é possível analisar a qualidade material e técnica desses programas, tendo-se em vista o seu conteúdo, as estruturas político-administrativas e a atuação dos atores envolvidos, tomando como foco o processo de implementação da política pública, ou seja, a descrição do "como" e a explicação do "porquê".

$\mathrm{Na}$ quinta e última fase descrita por Frey (2000), apreciam-se os programas já implementados no tocante a seus impactos efetivos. Trata-se de indagar os déficits de impacto e os efeitos colaterais indesejados para se 
poder traçar manobras políticas. Com base nessa avaliação de impacto, pode-se chegar à suspensão ou ao fim do ciclo político, ou ao início de um novo ciclo, com modificação do programa anterior. É importante destacar que o controle de impacto não precisa necessariamente ser realizado exclusivamente ao final do ciclo, mas deve acompanhar as fases do processo e conduzir a adaptações permanentes no programa, numa reformulação contínua da política.

Dentre as etapas descritas de implementação das políticas públicas, uma questão importante é a que designa o fato desencadeador da política pública. Por que dada questão deve ser objeto de uma política pública? Qual(ais) questão(ões) é(são) esta(s)?

A próxima seção deste trabalho analisa como a literatura sobre políticas públicas trata a questão da definição da agenda de políticas e quais são os seus determinantes.

\section{A definição da agenda de políticas públicas}

De acordo com Muller (2009), há uma evidência clara de que se há uma política pública há um problema a ser resolvido, e esse problema seria, portanto, sua origem. No entanto, mesmo considerando-se a existência de problemas - por exemplo, é um lugar comum que questões como poluição, delinquência e pobreza devam ser alvo de políticas públicas -, como se define o limiar de intensidade a partir do qual a ação pública deverá ser desencadeada?

Muller (2009) mostra que o reconhecimento do objeto das políticas públicas ocorre, na realidade, a partir de uma transformação da percepção dos problemas, sendo, portanto, necessariamente uma construção social, cuja configuração dependerá de múltiplos fatores inerentes à sociedade e ao sistema político. A questão está, então, em identificar os mecanismos concretos que determinam a inscrição deste problema na agenda de decisão.

A agenda política compreende, portanto, o conjunto de problemas reconhecidos como recorrentes no debate público ou na intervenção das autoridades políticas legítimas (Padioleau, 1982). Assim, conforme a definição de Kingdon (2006: 222), a agenda é a "lista de temas ou problemas que são alvo, em dado momento, de séria atenção tanto da parte 
das autoridades governamentais como das pessoas fora do governo, mas estreitamente associadas às autoridades".

Cobb e Elder (1994) identificam dois tipos de agenda política. O primeiro tipo é a agenda sistêmica da controvérsia política, que "consiste em todos os itens que são comumente percebidos pelos membros da comunidade política como merecedores de atenção pública" (p. 98). O segundo tipo é a agenda institucional, governamental ou formal, que se configura no "conjunto de itens explicitamente tido em consideração ativa e séria pelos decision makers" (p. 99), sendo que, por "explicitamente", os autores se referem a questões que envolvem a identificação de um problema que requer uma ação política, como o estabelecimento do salário mínimo, e, por "ativa e séria", os autores se referem a itens que entram na agenda formal de atividade pública e não apenas em outras formas de registro ou reconhecimento sem qualquer consideração explícita.

Enquanto as agendas sistêmicas são compostas por itens mais abstratos e genéricos, sem apresentação de alternativas para se lidar com o problema por exemplo, o fim da discriminação -, as agendas institucionais são mais específicas, concretas e limitadas a um certo número de itens exequíveis.

Tem-se que o acesso à agenda política nada tem de natural ou automático, sendo, ao contrário, um objeto de controvérsia social e política. De acordo com Muller (2009: 30), "a colocação na agenda é o produto do campo de forças que vai se construindo ao redor do problema". Assim, a transformação de um problema em objeto de intervenção política é sempre o produto de um trabalho específico realizado pelos atores políticos, que podem ser do sindicalismo, da política, de associações ou grupos criados para essa circunstância. E para compreender a emergência de uma política pública, é necessário começar identificando seus diferentes atores e compreendendo seus interesses e as relações que os unem.

Da mesma forma, Cobb e Elder (1994) julgam que a formação da agenda política não é neutra, mas sim permeada pelos interesses dos atores envolvidos, especialmente dos decision makers, uma vez que serão eles os guardiões da agenda formal, aqueles responsáveis com poderes legítimos por escolher dentre a pletora de itens competindo por atenção. Além disso, esses autores afirmam que são maiores as chances de influenciar os decision makers compositores da agenda quanto maior for o poder detido pelos grupos de interesse. Ou seja, grupos com menores poderes, como os de 
baixa renda, teriam maior dificuldade em adquirir essa legitimidade do que grupos empresariais, militares, políticos eleitos, entre outros.

Mas o que faz com que esses grupos de atores inseridos em determinadas arenas de poder num dado ciclo político se dediquem a determinado tema em detrimento de outros? O que faz com que um tema adquira maior relevância do que outro para ser considerado eletivo a uma agenda de políticas públicas?

De acordo com Kingdon (2006), os processos pré-decisórios da definição da agenda de políticas públicas permanecem como uma questão ainda pouco explorada na análise de políticas públicas. Apesar disso, a compreensão de por que os decision makers prestam mais atenção em dado tema do que em outros é fundamental para a disciplina de análise das políticas públicas.

Favre (1992) distingue quatro formas principais de emergência de determinados problemas à agenda política: (i) emergência progressiva e por múltiplos canais, a partir de uma situação tida como injusta, por exemplo; (ii) emergência instantânea, como uma catástrofe; (iii) ativação automática, sem que haja reivindicação ou demanda das populações envolvidas; (iv) emergência capturada, quando uma instituição exterior ao campo político se apropria do problema.

Cobb e Elder (1994), por sua vez, identificam dois tipos de mecanismos desencadeadores de problemas a serem levados às agendas políticas: os internos e os externos. Dentre os internos, encontram-se: a) catástrofes naturais; b) eventos humanos não antecipáveis, como motins, assassinatos de pessoas públicas ou de indivíduos privados, sequestros aéreos, entre outros; c) mudanças tecnológicas que estabelecem questões indiscutíveis este é o principal ponto de interesse de análise do presente trabalho; d) desequilíbrios na distribuição dos recursos, que levem a protestos civis e greves sindicais; e e) mudanças ambientais, como migrações ou explosões populacionais. Dentre os externos, os autores destacam: a) guerras; b) inovações em tecnologias bélicas envolvendo situações como controle de armamentos; c) conflitos internacionais; e d) alterações no alinhamento do ordenamento internacional.

Kingdon (2006) define três dinâmicas de processos que influenciam a montagem de agendas de políticas públicas: a) a da identificação dos 
problemas; b) a da proposição de políticas públicas; e c) a do engajamento político. Para o autor, esses processos são sequenciais, dado que as pessoas primeiramente reconhecem os problemas para depois gerarem propostas de mudanças por meio de políticas públicas, e, finalmente, se envolverem em atividades políticas como campanhas ou lobbies.

Considerando-se a primeira etapa de formação da agenda política, é importante que diferenciemos uma situação de um problema. Situações fortuitas dificilmente podem ser consideradas foco de atenção política. Mas, de acordo com Kingdon (2006), essa consideração pode-se alterar quando acreditamos que devemos fazer algo para mudá-la. A partir disso, a situação se torna um problema político e cabe aos governos tanto a definição de incluí-los na pauta da agenda quanto de excluí-los permanentemente.

Dessa forma, o reconhecimento de problemas é o primeiro passo crítico para o estabelecimento de uma agenda de políticas públicas e está diretamente relacionado ao grau de importância que o problema adquire na esfera pública. Kingdon (2006) afirma que determinados problemas são tão prementes que estabelecem agendas por si próprios.

A segunda etapa de formação da agenda política definida por Kingdon (2006) - a dos desdobramentos na esfera política - é uma etapa também muito importante tanto para a continuidade ou abandono de uma agenda política. De acordo com o autor, um novo governo, por exemplo, pode alterar completamente as agendas estabelecidas pelo governo anterior ao impor suas próprias concepções dos problemas e propostas. Além disso, a oposição de uma aliança poderosa de grupos de interesse pode dificultar que algumas iniciativas sejam contempladas.

Uma vez que se trata de uma etapa de cunho estritamente político, na configuração desta etapa são determinantes as estruturas de poder entre os agentes políticos, que se expressam com base nos processos de persuasão, de negociação e de consenso.

De acordo com Kingdon (2006), o consenso é formado na dinâmica da política mais por meio da negociação do que da persuasão, criando emendas em troca de apoio, atraindo políticos para alianças ou fazendo concessões em prol de soluções de maior aceitação. Por outro lado, quando participantes identificam problemas ou entram em acordo sobre certas propostas na dinâmica das políticas públicas, eles agem principalmente por meio da persuasão, organizando indicadores e defendendo que certas situações 
devem ser definidas como problemas ou que suas propostas satisfazem testes lógicos, tais como viabilidade técnica ou aceitabilidade.

A terceira etapa da formação da agenda definida por Kingdon (2006) é a do engajamento dos participantes no processo político. Nessa etapa os grupos de atores se distinguem entre participantes visíveis e invisíveis. De acordo com Kingdon (2006), os atores visíveis são aqueles que efetivamente estabelecem a agenda política e que têm notoriedade da imprensa e do público - presidente, assessores, membros do Congresso, mídia, partidos políticos e comitês de campanha -, enquanto os atores invisíveis são aqueles que influenciam a definição das alternativas de agendas possíveis, como os acadêmicos, consultores, burocratas de carreira e funcionários do Congresso.

As origens de uma política podem parecer um pouco obscuras e, portanto, difíceis de serem compreendidas, mas, por outro lado, há critérios bastante claros para a escolha de alternativas de agenda. Kingdon (2006) menciona alguns processos claros para a escolha de determinada alternativa de agenda em detrimento de outras, como critérios de viabilidade técnica, congruência com os valores da comunidade de especialistas na área, antecipação de possíveis restrições - como as orçamentárias -, aceitabilidade do público e receptividade dos políticos. E, aqui, poderíamos acrescentar os inegáveis processos de mudança tecnológica que tornam obsoletas antigas tecnologias que faziam parte da agenda, como no caso da banda larga no setor de telecomunicações, ou trazem inéditas demandas ou a necessidade de posicionamentos por parte dos atores políticos, como novas descobertas científicas na biotecnologia e genética.

Além desses critérios enfatizados pelo autor, podem-se somar, com base no aumento da importância dos procedimentos de governança assimilados nos últimos anos pelos governos neoliberais, os critérios tecnocráticos de avaliação de alternativas de políticas públicas. Os processos de liberalização e privatização desencadeados ao final do século passado levaram à necessidade da introdução de processos regulatórios e à criação de agências reguladoras para o estabelecimento de maiores níveis de competição nos diversos setores. Nesse ambiente que prima pela busca de eficiência e bemestar, análises de políticas públicas do tipo top-down, em que os políticos eleitos estão situados no topo do processo decisório, cederam espaço para 
medidas racionais de análise de políticas públicas, como as Análises de Impacto Regulatório (AIR).

De toda forma, não importando qual será a alternativa de agenda eleita, está claro que a probabilidade de um item se tornar prioritário é tanto maior quanto mais congruentes forem as três etapas de definição da agenda: problema, proposta de política pública e engajamento político.

A grande questão a que se dedica o presente trabalho é, na verdade, identificar quais seriam as situações que estabelecem os tipos de problemas que seriam considerados como possíveis eleitos dentro de uma agenda de políticas públicas.

De acordo com Kingdon (2006), situações podem suscitar problemas elegíveis para uma agenda de políticas públicas quando se abrem "janelas" para políticas públicas. Essas janelas nada mais são do que oportunidades para que os defensores de determinadas causas ofereçam suas soluções, ou chamem atenção para problemas que consideram importantes. $\mathrm{O}$ autor afirma que essas janelas são abertas tanto no âmbito dos problemas, quando se torna possível oferecer soluções para ele, quanto no âmbito das políticas, como ocorre na eleição de novos políticos, na mudança do clima político nacional, em um novo lobby poderoso ou na renovação de alguma legislação.

Neste trabalho, é explorada a ideia de que a mudança tecnológica origina novos problemas que as agendas de políticas são obrigadas a encarar, abrindo, portanto, janelas de oportunidades para a definição de novas políticas públicas ou alteração de antigas.

De acordo com Popper (2003), a emergência de tecnologias-chave traz desafios sem precedentes aos governos. Dentre essas tecnologias, o autor destaca aquelas com maiores possibilidades de transformações sociais no século XXI: tecnologias de informação e comunicação; biotecnologia; e nanotecnologia. Essas tecnologias possuem como característica comum o potencial de alterar as correlações de força através da promoção de um número relativamente pequeno de grupos de atores, ao mesmo tempo em que abre um campo potencial para importantes novos entrantes na esfera política, ou seja, empresas, organizações não-governamentais, entre outros.

Dentre os desafios que as novas tecnologias impõem aos governos como alocação de recursos para propósitos públicos e monitoramento e regulação da atividade privada em prol do benefício público -, Popper 
(2003) enfatiza a preocupação governamental que deve estar presente quando do estabelecimento de agendas de políticas que considerem os impactos dessas tecnologias na sociedade.

Para o autor, o principal risco incorrido pelos governos em ambientes e/ou setores tecnologicamente dinâmicos é a crescente divergência entre os ciclos de governo e aqueles do desenvolvimento tecnológico. Está claro que os processos de inovação e progresso técnico são processos inerentes ao sistema capitalista, sempre em constante desenvolvimento, destruindo suas velhas estruturas e estabelecendo novas (Schumpeter, 1982). Dessa forma, não parece surpreender que as políticas públicas tenham sempre que caminhar a reboque dos avanços técnicos, inserindo essas mudanças em suas agendas políticas. Assim, um dos grandes desafios dos governos é o de não deixar que as agendas formadas com o intuito de incluir certos avanços técnicos já estejam defasadas ao serem estabelecidas.

Além disso, outro importante desafio dos governos apresentado por Popper (2003) ao lidarem com o tema da mudança técnica é que a sua esfera de ação se torna cada vez menos clara, uma vez que as novas tecnologias atingem diretamente um grande número de agentes e interesses.

Soma-se a esse desafio o fato de que, quando estamos lidando com o tema da mudança técnica, estamos tratando de processos e de ambientes permeados pela incerteza, o que, por si só, já se traduz em um grande e importante desafio para a definição e gerenciamento de políticas públicas. Esse processo é, de acordo com Popper (2003), ainda mais desafiador quando se consideram tecnologias revolucionárias ou disruptivas ${ }^{1}$, que afetam contundentemente as instituições econômicas, sociais e políticas.

O próximo item deste trabalho analisa a alteração da agenda de universalização de serviços de telecomunicação no Brasil, que teve como base o processo de digitalização das redes e o aumento da importância dos serviços de banda larga na pauta de agenda de políticas públicas do País.

${ }^{1}$ De acordo com Freeman e Perez (1988), as tecnologias revolucionárias ou disruptivas são aquelas que geram efeitos que se alastram por toda a economia, engendrando profundas mudanças estruturais que requerem uma igualmente profunda transformação no arcabouço institucional e social. As Tecnologias de Informação e Comunicação (TIC) são consideradas pelos autores como um exemplo dessas tecnologias, ou do novo paradigma técno-econômico que se origina a partir dos anos 1980. 


\section{A agenda de universalização da banda larga no Brasil}

As duas últimas décadas alteraram o panorama do setor de telecomunicações de forma ampla e contundente. A privatização dos monopólios estatais que se iniciou na década de 1990 em diversas partes do mundo deu impulso ao processo de globalização desse mercado, deflagrando um movimento acelerado de fusões e aquisições, especialmente por parte dos países desenvolvidos, que passaram a buscar novos ganhos de escala.

No Brasil, o processo de liberalização do setor de telecomunicações se iniciou em 1995, com a quebra do monopólio da estatal Telebras, a privatização das empresas de telefonia e a aprovação da Lei Geral de Telecomunicações (LGT, Lei 9.472/97). Esse processo dotou o país de um novo modelo institucional para as telecomunicações, que se baseou em três princípios normativos: a) universalização do Serviço Telefônico Fixo Comutado (STFC), prestado no regime público; b) competição na telefonia fixa entre operadoras dos regimes público e privado, e competição na telefonia móvel com abertura de bandas de frequência sucessivas para exploração do serviço; e c) regulação por agência autônoma, a partir da criação da Anatel (Ramos, 2010).

A LGT define as obrigações de universalização como:

"as que objetivam possibilitar o acesso de qualquer pessoa ou instituição de interesse público a serviço de telecomunicações, independentemente de sua localização e condição sócioeconômica, bem como as destinadas a permitir a utilização das telecomunicações em serviços essenciais de interesse público" (Cap. I, art. 79, $\S 1^{\circ}$ ).

Além disso, ficou estipulado que "serviço de telecomunicações em regime público é o prestado mediante concessão ou permissão, com atribuição a sua prestadora de obrigações de universalização e de continuidade" (LGT, Cap. II, art. 63, parágrafo único).

A LGT também estabelece que cabe ao Poder Executivo a aprovação por decreto do Plano Geral de Metas de Universalização, que, em sua primeira edição (Decreto 2.592/98), determinou, além da meta de universalização da telefonia fixa de uso individual, a obrigatoriedade de instalações de Telefones de Uso Público (TUP) - os conhecidos "orelhões" -, que 
"permite, a qualquer pessoa, utilizar (...) o acesso ao STFC independentemente de assinatura ou inscrição junto à prestadora (Cap. I, art. $3^{\circ}$, inciso II).

A posterior alteração do PGMU (Decreto 4.769/03) passou a incluir as metas de instalação de Postos de Serviços de Telecomunicações (PST), que se configuravam em "um conjunto de instalações de uso coletivo, mantido pela concessionária, dispondo de, pelo menos, TUP e $\mathrm{TAP}^{2}$, e possibilitando $\mathrm{o}$ atendimento pessoal ao consumidor" (Cap. I, art. $3^{\circ}$, inciso VIII).

Como se vê, as obrigações originais de universalização das telecomunicações no Brasil eram bastante restritas e voltadas, principalmente, à massificação dos serviços de voz. Essa agenda de políticas públicas ignorava, portanto, "as potencialidades da convergência de plataformas tecnológicas e de serviços e suas possíveis repercussões sobre a definição de serviços essenciais de telecomunicações" (Tapia et al, 2001: 264).

De fato, rápidos foram os avanços nas tecnologias de informação e comunicação desde então, representados, sobretudo, pelo processo de digitalização das antigas redes analógicas de telecomunicações e pelo subsequente surgimento das redes de nova geração [Next Generation Networks - NGN].

O processo de digitalização das redes de telecomunicação alterou o tipo, a quantidade e a velocidade dos serviços oferecidos. As NGN passaram a integrar os anteriormente separados serviços de voz, dados e mídia em uma mesma infraestrutura, como, por exemplo, internet em banda larga, redes móveis 3G, LANs wireless e televisores digitais, tendo, como base, principalmente, a plataforma IP (OCDE, 2004).

Como se vê, as mudanças tecnológicas ocorridas recentemente no setor de telecomunicações alteraram as formas de comunicação da sociedade e, por conseguinte, as demandas estabelecidas por ela. Se, por um lado, as

2"Terminal de Acesso Público - TAP é aquele que permite, a qualquer pessoa, utilizar, por meio de acesso de uso coletivo, o STFC, independentemente de assinatura ou inscrição junto à prestadora, incluindo, ainda, funções complementares que possibilitem o uso do STFC para conexão a Provedores de Acesso a Serviços de Internet (PASI), de livre escolha do usuário, e envio e recebimento de textos, gráficos e imagens, por meio eletrônico" (Decreto 4.769/03, Cap. 1, art. $3^{\circ}, \mathrm{XI}$ ).

Revista de Direito, Estado e Telecomunicações, v. 3, n. 1, p. 89-110 (2011)

DOI: https://doi.org/10.26512/lstr.v3i1.21668 
empresas passaram a oferecer serviços convergentes, como os multiple play, ou "combos", no Brasil, impondo novos desafios para a regulação da concorrência entre operadoras de redes antes distintas, por outro, os consumidores passaram a requerer cada vez maiores bandas de acesso a conteúdo IP, seja voz, dados ou mídia, em mais alta velocidade, aumentando a importância do acesso à internet em banda larga ${ }^{3}$ em detrimento das outras formas de comunicação.

Nesse panorama, o mercado de telefonia fixa tem perdido cada vez mais espaço para os novos tipos de serviços, principalmente, telefonia móvel e internet em banda larga. ${ }^{4}$ Como mostra a tabela 1, entre 2003 e 2009, o número de assinantes de telefones fixos no Brasil se estabilizou em torno de 21 em cada 100 habitantes. Em contrapartida, o número de assinantes de celulares cresceu $23 \%$ ao ano no mesmo período, alcançando o patamar de penetração de $90,6 \%$ em 2009 . O crescimento no número de assinantes de banda larga fixa foi ainda maior, apesar de partir de uma base baixa de penetração de $0,7 \%$, em 2003 , e de $42 \%$ ao ano, atingindo um patamar de penetração de quase 6 assinantes a cada 100 habitantes $^{5}$ em 2009.

\begin{tabular}{|l|c|c|c|c|c|c|c|c|c|}
\hline & $\mathbf{2 0 0 3}$ & $\mathbf{2 0 0 4}$ & $\mathbf{2 0 0 5}$ & $\mathbf{2 0 0 6}$ & $\mathbf{2 0 0 7}$ & $\mathbf{2 0 0 8}$ & $\mathbf{2 0 0 9}$ & $\Delta$ total & $\Delta$ anual \\
\hline Telefone Fixo & 21,8 & 21,7 & 21,5 & 20,8 & 20,9 & 21,6 & 21,7 & $0 \%$ & $0 \%$ \\
Telefone celular & 25,8 & 35,9 & 46,6 & 53,2 & 63,6 & 79,2 & 90,6 & $251 \%$ & $23 \%$
\end{tabular}

${ }^{3}$ A União Internacional de Telecomunicações (UIT) adota como definição de internet banda larga a capacidade de transmissão que é superior à taxa primária de ISDN [Integrated Services Digital Network] a 1,5 ou 2,0 Megabits por segundo.

${ }^{4}$ Os dados apresentados são o do serviço de banda larga fixa, que inclui as tecnologias ADSL, TV por assinatura (TV a Cabo ou MMDS), rádio e via satélite. Com relação à banda larga móvel, como a $3 \mathrm{G}$ - via celulares ou terminais de acesso (modems) -, é importante que se reconheça que a quantidade de aparelhos celulares 3G e de terminais de acesso móvel (modems) cresceu muito nos últimos anos, alcançado 19,5 milhões de aparelhos (13,6 milhões de celulares com tecnologia WCDMA e 5,9 milhões de modems) até novembro de 2010, de acordo com dados da Anatel. No entanto, não há estimativas confiáveis a respeito do número de acessos em banda larga via pacotes de dados a partir desses equipamentos. Por isso, optou-se, nesse artigo, por utilizar exclusivamente estatísticas referentes ao acesso em banda larga fixa.

${ }^{5}$ Esse valor ainda é baixo quando comparado à média de $24 \%$ de penetração da banda larga em países da OCDE e a alguns países em desenvolvimento, como Chile (8,5\%), Argentina (8\%), Turquia (7,8\%) e México (7\%) (ITU, dados de 2008). 
\begin{tabular}{|l|l|l|l|l|l|l|l|l|l|} 
Banda Larga fixa & 0,7 & 1,3 & 2,1 & 3,1 & 4,1 & 5,3 & 5,8 & $729 \%$ & $42 \%$ \\
\hline
\end{tabular} Fonte: Anatel, Teleco e ITU.

Número de assinantes por 100 habitantes.

Tabela 1 - Brasil: evolução da difusão dos serviços de telecomunicação

Além disso, a conexão à internet em banda larga tem gerado, nos últimos anos, ganhos de produtividade e de crescimento em todo o mundo. Recentes estudos conduzidos pelo Banco Mundial mostram que a cada $10 \%$ de aumento na penetração de serviços de banda larga obtém-se $1,3 \%$ de crescimento no PIB dos países (Quiang e Rosotto, 2009).

A questão de como adequar a agenda de políticas públicas das telecomunicações ao cenário convergente tornou-se, portanto, a preocupação central no contexto da universalização de serviços de comunicação. Com a liberalização dos mercados e o acirramento do processo competitivo, os governos voltam suas atenções a formas de provisão de serviços de comunicação em áreas mais remotas, de menor densidade populacional e de mais baixa renda, que tendem a não ser foco dos investimentos das empresas privadas.

Além disso, na medida em que o direito à comunicação é um direito fundamental, conforme previsto na Constituição Federal de 1988 (art. 5º, $\S 2^{\circ}$ ), e, tendo em vista que a internet tem se traduzido no instrumento economicamente viável, socialmente eficaz e tecnologicamente adequado para o exercício desse direito fundamental (Felizola, 2010), tornou-se premente alterar as agendas regulatórias direcionadas à universalização das telecomunicações, abrangendo a concepção dinâmica do escopo dos serviços universais que já estava prevista na regulação do setor.

De fato, o PGMU já contempla uma concepção dinâmica do escopo de serviço universal, abarcando as alterações viabilizadas pelo progresso técnico: "a Anatel, em face de avanços tecnológicos e de necessidades de serviços pela sociedade, poderá propor a revisão do conjunto de metas que objetivam a universalização do serviço" (PGMU, 1998, Cap. I, art. $2^{\circ}$, § $2^{\circ}$ ).

Assim, o Decreto 6.424/08 revisou o PGMU, com o objetivo de adequar a regulamentação do STFC ao novo cenário convergente das telecomunicações, incluindo a disponibilização de infraestrutura para a massificação de acessos em banda larga. De acordo com essa revisão, as 
metas de instalação de PSTs foram substituídas pela obrigação de instalação de backhaul - infraestrutura física para banda larga.

O Decreto 6.424/08 define, portanto, que "backhaul é a infraestrutura de rede de suporte ao STFC para conexão em banda larga, interligando redes de acesso ao backbone da operadora" (art. $3^{\circ}$, inciso XIV), e, além disso, estabelece, no art. 13, que "a concessionária deverá instalar backhaul nas sedes dos municípios e localidades ainda não atendidos em suas respectivas áreas geográficas de concessão (...) até 31 de dezembro de 2010”.

Após as revisões estabelecidas no decreto do PGMU, outras normas atinentes ao setor de telecomunicações passaram a considerar a importância da banda larga em detrimento das tecnologias de comunicação anteriormente difundidas. O Decreto 6.654/08 revoga o anterior Decreto 2.534/98, aprovando a revisão do Plano Geral de Outorgas (PGO), e estabelece que "as concessionárias (...) devem (...) cumprir com as obrigações de universalização, inclusive aquelas relacionadas à ampliação das redes do serviço que suportem a banda larga" (art. $7^{\circ}$, inciso I).

A Resolução da Anatel n. 516, de 30 de outubro de 2008, inclui no Plano Geral de Atualização da Regulamentação das Telecomunicações (PGR) a diretriz de massificação do acesso em banda larga:

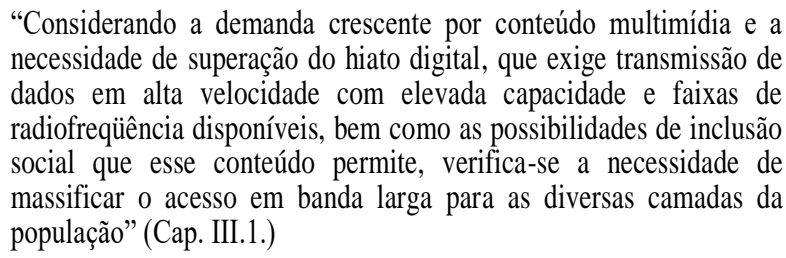

Além disso, a Anatel aprovou a Resolução n. 527, de 08 de abril de 2009, que regulamenta as condições de uso de radiofrequencias por sistemas de banda larga por meio de redes elétricas, o que se traduziria, de acordo com alguns especialistas, numa grande possibilidade de universalização da banda larga, haja vista a elevada capilaridade das redes de energia elétrica no país (Berbert, 2009).

Além das revisões do PGMU, das alterações do PGO, PGR e do estabelecimento da Resolução n. 527, que passaram a fazer menção expressa 
à banda larga, foi instituído, no ano, de 2010, o Plano Nacional da Banda Larga (Decreto 7.175/10), com o objetivo de:
"(...) fomentar e difundir o uso e o fornecimento de bens e serviços
de tecnologias de informação e comunicação, de modo a:
I - massificar o acesso a serviços de conexão à Internet em banda larga;
II - acelerar o desenvolvimento econômico e social;
III - promover a inclusão digital;
IV - reduzir as desigualdades social e regional;
$\mathrm{V}$ - promover a geração de emprego e renda;
VI - ampliar os serviços de Governo Eletrônico e facilitar aos cidadãos o uso dos serviços do Estado;
VII - promover a capacitação da população para 0 uso das tecnologias de informação; $\mathrm{e}$
VIII - aumentar a autonomia tecnológica e a competitividade brasileiras" (PNBL, 2010, art. $1^{\circ}$ ).

O PNBL emula planos recentemente levados a cabo por diversos países, como Estados Unidos, Austrália e Alemanha (Qiang, 2009), que, a partir da percepção da crescente essencialidade do acesso à internet em banda larga para a participação na sociedade da informação, buscam massificar o acesso a essa tecnologia por meio de diversas iniciativas tomadas em âmbito nacional.

Dessa forma, todas essas agendas estabelecidas para a universalização da banda larga surgem da constatação de que o modelo institucional das telecomunicações brasileiras centrado na universalização da telefonia fixa comutada já não mais atende às necessidades advindas da internet em redes de alta capacidade e alta velocidade, tendo sido superado pelo desenvolvimento das tecnologias de informação e comunicação mais recentes (Ramos, 2010).

Observa-se, pois, que as janelas políticas (Kingdon, 2006) criadas pela digitalização das redes de telecomunicação, que estabeleceu como ícone de comunicação da atualidade o acesso à internet em banda larga, se traduziram na conquista do regulador em contemplar uma série de agentes e interesses não tão claros - uma vez que explicitados em um ambiente tecnológico em constante mudança (Popper, 2003) - em um propósito único.

Constata-se, então, que o aumento da popularidade da banda larga alterou a percepção dos problemas (Muller, 2009) em comunicação, 
obtendo explicitamente uma consideração ativa e séria pelos decision makers (Cobb e Elder, 1994), e, portanto, sendo incluído na agenda formal das telecomunicações no Brasil. Com isso, o advento da digitalização das redes de telecomunicações também propiciou o engajamento político (Kingdon, 2006) dos defensores da alteração do escopo da agenda de universalização em favor da banda larga.

Assim, a regulação para universalização da banda larga reflete uma agenda balizadora de interesses do campo de força que se constitui ao redor do problema (Muller, 2009), que expressa o alcance do consenso e engajamento político em torno de uma proposta amplamente aceita. Neste caso, podem-se destacar os interesses expressos por parte do governo, que estabelece os decretos, representa os interesses das populações mais pobres e menos favorecidas e busca ganhos de produtividade e crescimento advindos da expansão da banda larga; das operadoras do serviço de banda larga e das concessionárias, que têm a obrigatoriedade da expansão do serviço; dos fabricantes de equipamentos de infraestrutura de banda larga e de demais equipamentos para a utilização do serviço, como computadores, celulares $3 \mathrm{G}$ etc; dos usuários dos domínios público e privado, vale dizer domicílios e empresas; dos usuários beneficiados diretamente por programas de expansão desse tipo de serviço, tais como escolas, população de baixa renda e de localidades antes não atendidas pelo serviço, entre outros.

Esses interesses nada mais são do que controvérsias de atores relacionadas à melhor forma de se abordarem problemas percebidos como imprescindíveis de serem conduzidos pelas políticas públicas e que, diante de um inegável avanço técnico, impôs a todos eles a necessidade de se posicionarem e de buscarem o consenso para que todos possam, de alguma forma, desfrutar da nova realidade tecnológica do setor de telecomunicações.

\section{Conclusões}

A formação da agenda de políticas públicas ocorre tendo como base a percepção de problemas relevantes por parte dos participantes do campo de força político. Diversos são os aspectos que merecem destaque na agenda política: eventos naturais e humanos não antecipáveis, como catástrofes e motins, desequilíbrios na distribuição dos recursos, entre outros fatores que 
tornam necessários o posicionamento e a intervenção dos governos na esfera pública.

O avanço tecnológico impõe grandes desafios à formulação de agendas de políticas públicas, em especial daquelas voltadas a setores tecnologicamente dinâmicos. Como visto, o progresso tecnológico do setor de telecomunicações, com o advento da digitalização das redes e a alteração nas formas de comunicação da sociedade - de voz para acesso a conteúdo em banda larga -, alterou a percepção dos agentes envolvidos e impactados por essa mudança tecnológica e acarretou a necessidade de alteração e formação de novas agendas voltadas à massificação do acesso a esse serviço.

Essa mudança na agenda foi percebida como necessária e premente para que não houvesse excluídos do direito fundamental à comunicação, mas também para que o país pudesse desfrutar dos ganhos de produtividade e de crescimento advindos na difusão desse acesso.

Constata-se também que, em se tratando de um setor dinâmico como o de telecomunicações, haverá sempre um claro descompasso entre o desenvolvimento das agendas regulatórias e da mudança tecnológica. Dessa forma, a montagem da agenda regulatória é concebida via de regra a reboque da dinâmica tecnológica do setor.

Com isso, outro grande desafio que se coloca à montagem de agendas de políticas públicas em setores tecnologicamente dinâmicos é a de que estas sejam constantemente revistas, de modo a conceber o problema a que se dedicam de forma dinâmica, promovendo constantes debates com a sociedade e a participação de todos os atores envolvidos nesse campo político.

Assim, em se tratando de agendas regulatórias voltadas à universalização de serviços de telecomunicação, estas devem sempre buscar acompanhar os avanços tecnológicos, mesmo que com certo descompasso, de forma que não se criem abismos entre as demandas e as ofertas tecnológicas expressas pela sociedade e o posicionamento do regulador na garantia da massificação do acesso a esses serviços. 


\section{Bibliografia}

COBB, R.; ELDER, C. (1994). Issues and Agendas. In: THEODOULOU, S.; CAHN, M. (org.). (1994). Public Policy - The Essential Readings. New Jersey: Prentice Hall.

FAVRE, P. (1992). L'émergence des problemès dans le champ politique. In: FAVRE, P. (org.). Sida et politique: Les premiers affrontements, 19811987. Paris: L'Harmattan.

FELIZOLA, P. A. M. (2010). A fundamentalidade do direito à comunicação: internet e participação no contexto da sociedade em rede. Políticas públicas de acesso à internet no Brasil. In: Anais da IV Conferência ACORN-REDECOM, Brasília, DF, de 14 e 15 de maio.

FREEMAN, C.; PEREZ, C. (1988). Structural Crisis of Adjustment, Business Cycles and Investment Behaviour. In: DOSI, G. [et al.] (org.). Technical Change and Economic Theory. London: Francis Pinter.

FREY, K. (2000). Políticas públicas: um debate conceitual e reflexões referentes à prática da análise de políticas públicas no Brasil. In: Planejamento e Políticas Públicas 21: 211-259.

JONES, C. (1970). An Introduction to the Study of Public Policy. Belmont: Duxbury Press.

KINGDON, J. (2006). Como chega a hora de uma ideia? In: SARAIVA, E.; FERRAREZI, E. (orgs.). (2006). Políticas públicas: coletânea, Vol. 1. Brasília: ENAP.

MÉNY, Y.; THOENIG, J-C. (1989). Politiques Publiques. Paris: PUF.

MUller, P. (2009). Les Politiques Publiques. Paris: PUF. (Collection Que sais-je?).

OCDE. (2004). The Implications of Convergence for Regulation of Electronic Communications. Directorate for Science, Technology and Industry.

PADIOLEAU, J-G. (1982). L'État au concret. Paris: PUF.

PEREIRA, P. A. P. (2008). Política Social - Temas e Questões. São Paulo: Cortez.

POPPER, S. (2003). Technological Change and the Challenges for $21^{\text {st }}$ Century Governance. In: TEICH, A.; NELSON, S.; LITA, S.; HUNT, A. (org.). (2003). AAAS Science and Technology Policy Yearbook. 
Disponível em: http://www.aaas.org/spp/yearbook/2003/yrbk03.htm. Acesso em: maio de 2010.

QIANG, C. Z. W. (2009). Broadband Infrastructure Investment in Stimulus Packages: relevance for developing countries. Banco Mundial. QIANG, C. Z. W.; ROSSOTTO, C. (2009). Economic Impacts of Broadband. In: Information and Communication for Development 2009. Banco Mundial. Disponível em: http://go.worldbank.org/NATLOH7HV0. RAMOS, M. C. (2010). Crítica a um Plano Nacional de Banda Larga: uma perspectiva de economia política das políticas públicas. In: Anais da IV Conferência ACORN-REDECOM, Brasília, DF, de 14 e 15 de maio.

ROMANO, J. O. (2009). Política nas políticas: um olhar sobre a agricultura brasileira. Rio de Janeiro: Mauad X e Edur.

SCHUMPETER, J. (1982). A Teoria do Desenvolvimento Econômico. São Paulo: Abril Cultural.

TAPIA, J.; BESSA, V.; DALMAZO, R. (2001). Política de serviço universal e liberalização das telecomunicações: a experiência brasileira no contexto de uma agenda de transição. In: Ensaios FEE 22(1): 261287. 